\title{
Skull Metastasis in Prostate Cancer: A Compilation of Four Cases along with Review of the Literature
} \author{
hamed SIMPORE ${ }^{1}$, Bienvenue Désiré $K Y^{1}$ and Aïssata OUEDRAOGO ${ }^{1}$ \\ ${ }^{1}$ Urology Department, University Hospital Yalgado Ouedraogo, Ouagadougou, Burkina Faso \\ ${ }^{2}$ Department of Surgery, Federal Medical Center Nguru, Yobe, Nigeria
}

Brahima KIRAKOYA ${ }^{1 *}$, Fasnewindé Aristide KABORE ${ }^{1}$, Babagana Mustapha ABUBAKAR (D), Mo-

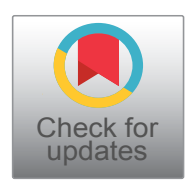

*Corresponding author: Brahima KIRAKOYA, University Hospital Yalgado Ouedraogo, 07 BP 5542, Ouagadougou, Burkina Faso, Tel: 00226-78-84-13-88

\begin{abstract}
Background: Skull metastasis in prostate cancer is rare and is seen in advanced cases. We study four cases seen in our facility with the aim of identifying challenges in making diagnosis and treatment of these patients. We also reviewed the literature.

Observations: This study involved four men age 55, 65, 66 and 69 years. In two cases, the skull metastases were discovered during evaluation for primary skull swelling, no lower urinary tract symptoms (LUTS) at presentation. In the other two cases, skull metastases were discovered when the patients were evaluated for metastases after the diagnosed prostate cancer. There was prostatic adenocarcinoma in all the cases. Treatment offered consists of androgen deprivation therapy among other modalities.

Conclusion: Metastasis of prostate cancer to the skull can be without urinary symptoms. It may be occasionally consider as primary skull tumor, therefore, any skull deformity in an elderly man above 60 years of age should raise high index of suspicion.
\end{abstract}

\section{Keywords}

Metastasis, Skull, Prostate cancer

\section{Introduction}

Prostate cancer is the commonest male cancer and one of the most common cause of death in men [1]. It is known for its potential metastasis to the bone. In men, it is the commonest cause of secondary bone tumor [2]. Metastasis is frequently to the axial skeleton. Skull metastases in prostate cancer is rare, accounting for less than $2 \%$ of all metastases [3]. It often involves the base of the skull and it has a diverse clinical manifestation [4].

We present four patients with skull metastases from cancer of the prostate; our aim is to review the diagnostic and therapeutic challenges in the management of these patients. We also review the literature.

\section{Observations}

\section{Patient No. 1}

Mr. B.C, is a 66-years-old man who presented to Neurosurgery Department with swelling in the left parietal region. Subsequent evaluation revealed high PSA level of $9,202 \mathrm{ng} / \mathrm{ml}$ which warranted referral to urology unit. The swelling noticed about a year prior to presentation. It was painless and slowly increasing in size. There was no neurological or lower urinary tract symptom (LUTS). Physical examination revealed a left firm, non-tender parietal mass. The scalp and hair appears normal. Digital rectal examination revealed enlarged, hard and nodular prostate. Renal function was normal. Prostate biopsy showed adenocarcinoma, Gleason score $6(3+3)$. Computed Tomography (CT) of the skull showed a left well-circumscribed parietal mass with bony exostosis inside and outside the skull. The overlying and underlying structures were normal (Figure 1). Bone scintigraphy showed areas of high radioactive absorption at the level of the parietal mass, as well as the left humeral head and the ribs. The patient underwent androgen 

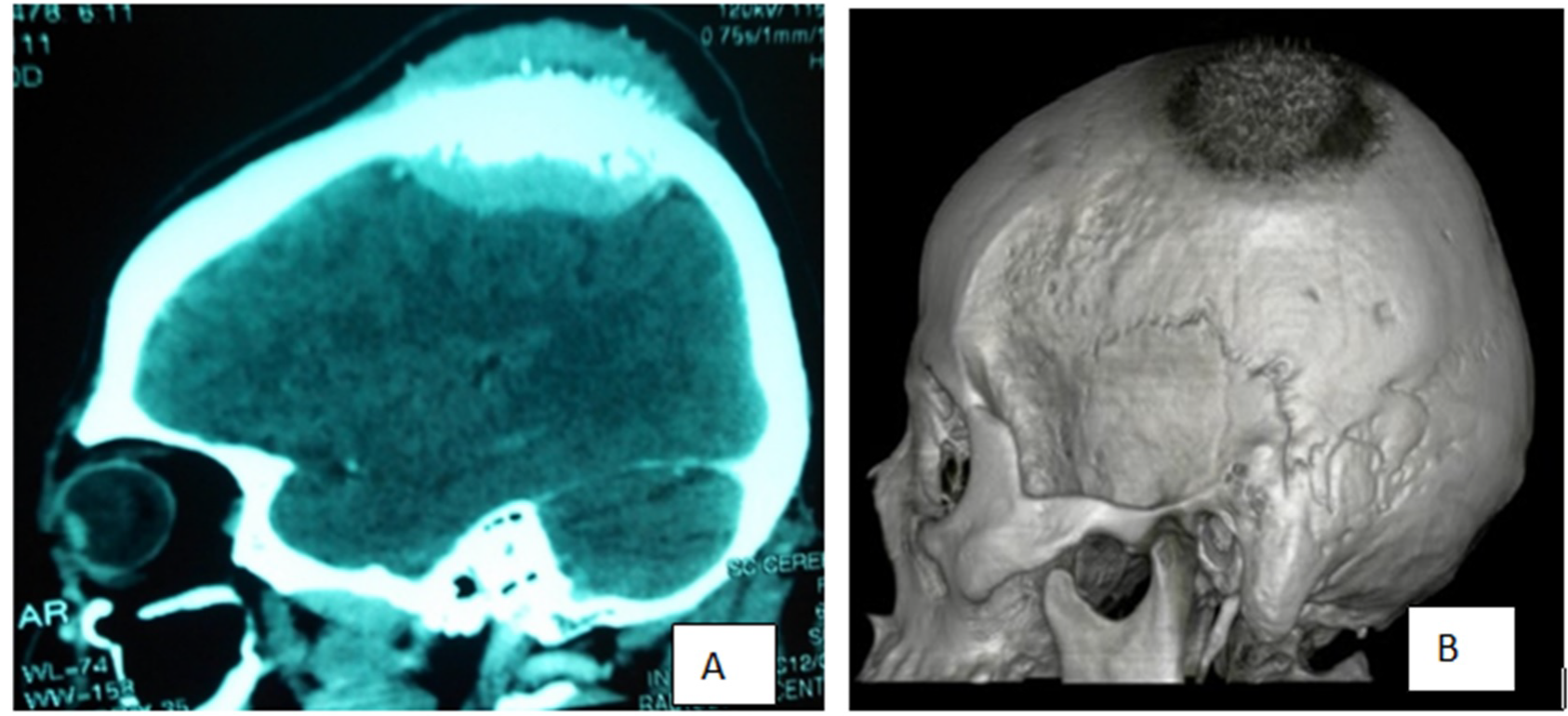

Figure 1: Brain CT showing osteoblastic mass of the cranial vault A) Soft tissue window; B) Reconstructed image.

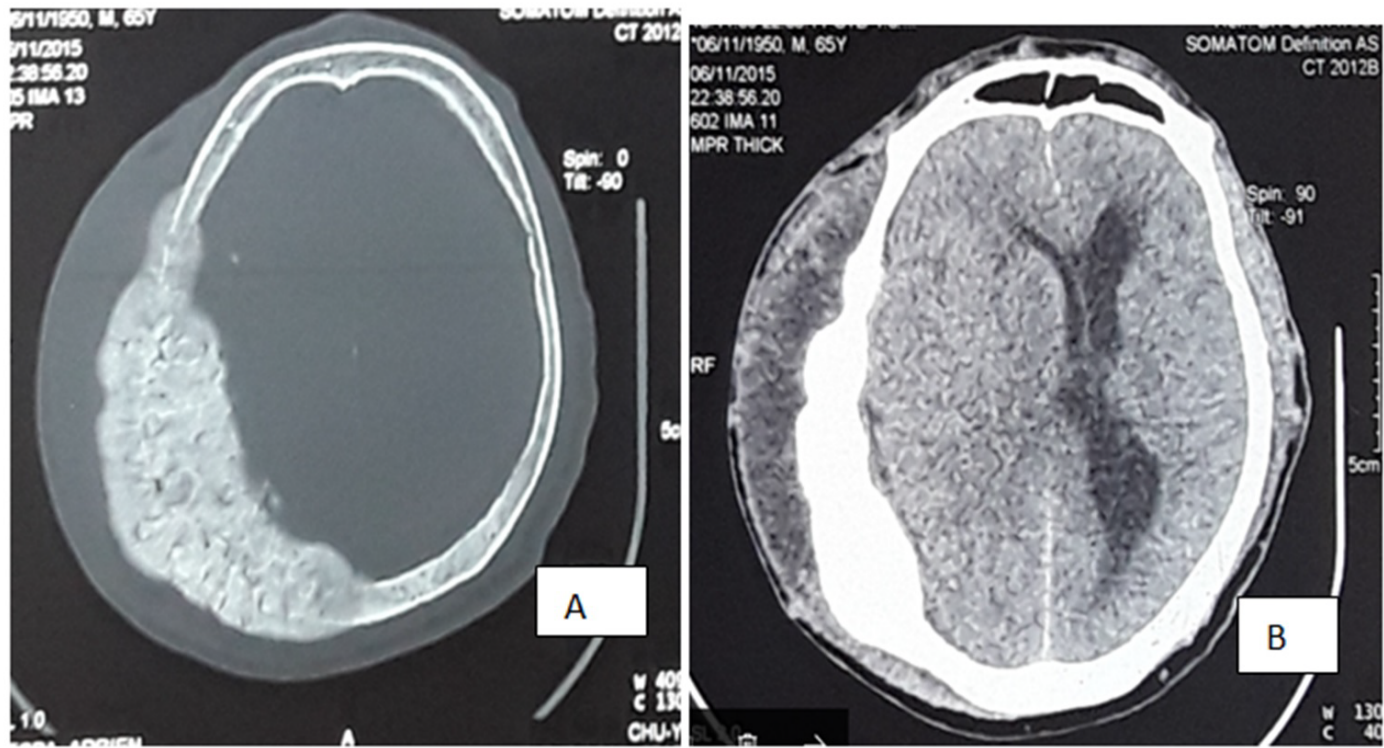

Figure 2: Brain CT showing right temporal bone mass compressing on the brain. A) Bone window showing an osteoblastic lesion of the right temporal bone; B) Soft tissue window showing a swelling of the extracranial tissues and brain compression.

privation therapy using Cyproterone $300 \mathrm{mg} /$ day because he cannot afford more appropriate treatment (LHRH analog, Abiraterone, chemotherapy). He had regular follow up, the lowest PSA recorded was $3 \mathrm{ng} /$ $\mathrm{ml}$ after 8 months of treatment. The parietal swelling has reduced in size. At $18^{\text {th }}$ month of treatment, the PSA level rose to $102 \mathrm{ng} / \mathrm{ml}$ and the serum Testosterone was $0.1 \mathrm{ng} / \mathrm{ml}$. The general condition of the patient gradually deteriorated and he died few months later.

\section{Patient No. 2}

S.A is a 65-years-old man who was also referred from Neurosurgery Department where he presented with right temporal swelling of 9 months duration. The swelling was painless but there was associated right ear hearing impairment. PSA level was found to be $6,909 \mathrm{ng} / \mathrm{ml}$ during the course of his evaluation. There was nocturia of 4 to 5 times per night, no other LUT or urological symptoms. Physical examination revealed a firm and non-tender mass involving the whole right temporal region. The overlying skin appears normal. On digital rectal examination, the prostate was small, hard and irregular. Ear-nosethroat (ENT) examination revealed right conductive deafness due to temporal bone deformity and partial obstruction of the external auditory canal. The histological examination of the prostate biopsy samples revealed adenocarcinoma. Computer tomography of the brain showed thickening of the right temporal bone with prominent bony exostosis compressing on the brain (Figure 2). Patient had bilateral orchi- 
ectomy. Follow up at 2, 15 and 24 months revealed PSA levels of $295 \mathrm{ng} / \mathrm{ml}, 268 \mathrm{ng} / \mathrm{ml}$ and $100 \mathrm{ng} / \mathrm{ml} \mathrm{re-}$ spectively with a significant improvement of clinical symptoms and signs, as well as a reduction in size of the temporal swelling.

\section{Patient No. 3}

Mr. O.S, is a 55-years-old man who presented with difficulty in passing urine characterized by poor stream, straining on micturition and nocturia of 7 to 10 times per night. There was progressive occipital swelling which was painless with no neurological symptom. No history of prostate cancer in his family. The general condition of the patient was good. There was well-circumscribed, painless occipital mass with normal overlying scalp.

On digital rectal examination, there was enlarged prostate, which was hard and nodular. Total PSA was $715.10 \mathrm{ng} / \mathrm{ml}$ and histology of biopsy samples of the prostate revealed adenocarcinoma of the prostate, Gleason score $8(4+4)$. The kidney function was normal. Brain CT showed a marked occipital osteolytic lesion with significant loss of bone substance (Figure 3).

Patient had anti-androgen therapy with Cyproterone acetate $300 \mathrm{mg} /$ day as patient cannot afford medical castration and he also refuses surgical castration. The patient was seen after a month with a total PSA of $80 \mathrm{ng} / \mathrm{ml}$. There was also improvement in the urinary symptoms and reduction of the occipital swelling. At 3 months, PSA increased to $128 \mathrm{ng} /$ $\mathrm{ml}$ and serum testosterone was $0.2 \mathrm{ng} / \mathrm{ml}$. Check-up CT brain revealed an increase of the initial occipital lesion with appearance of a new osteolytic mass in the left temporal region.

\section{Patient No. 4}

Mr. B.O is a 69-year-old man who was seen in urology clinic with LUTS characterized by poor stream and nocturia of 5 times per night. Symptoms have been progressive for 3 months. On examination, patient's general condition was preserved. On digital rectal examination, the prostate was enlarged, non-tender, asymmetrical, hard and nodular. On examination of the scalp, there was right well-circumscribed and hard parietal mass. Total PSA was $100 \mathrm{ng} / \mathrm{ml}$ and pathological examination of the biopsy samples of the prostate revealed a prostatic adenocarcinoma, Gleason score $6(3+3)$. Bone scintigraphy showed multiple metastatic lesions especially in the right parietal area, the left $1^{\text {st }}$ rib and left femoral epiphysis.

Treatment offered consists of androgen privation therapy by surgical castration. Check-up after 3 months revealed significant reduction of the parietal mass and PSA had reduced to $46 \mathrm{ng} / \mathrm{ml}$.

\section{Discussion}

As any bones in the body, the skull can be a site for tumor metastasis. The diagnosis is usually made clinically based on high index of suspicion. There may no need for biopsy of the skull mases especially when the primary tumor has been identified. Our diagnosis was based on clinical suspicion. We did not histologically confirm the metastases because the primary tumor has been identified. This has spares the patient from the risk of a cranial biopsy and its complication.

Cancer of the prostate, breast and lung are the main source of skull metastases accounting for more than $70 \%$ of secondary tumors of the skull [5]. In men, cancer of the prostate is the commonest cause of skull metastasis [6]. There may no be any urinary symptoms or any clinical manifestation to indicate the primary origin of the tumor. This was the case in two of the four cases presented in this series; they both have no urological symptoms at presentation. The mass in the skull has no specific clinical feature and no urological symptoms. Therefore, any swelling
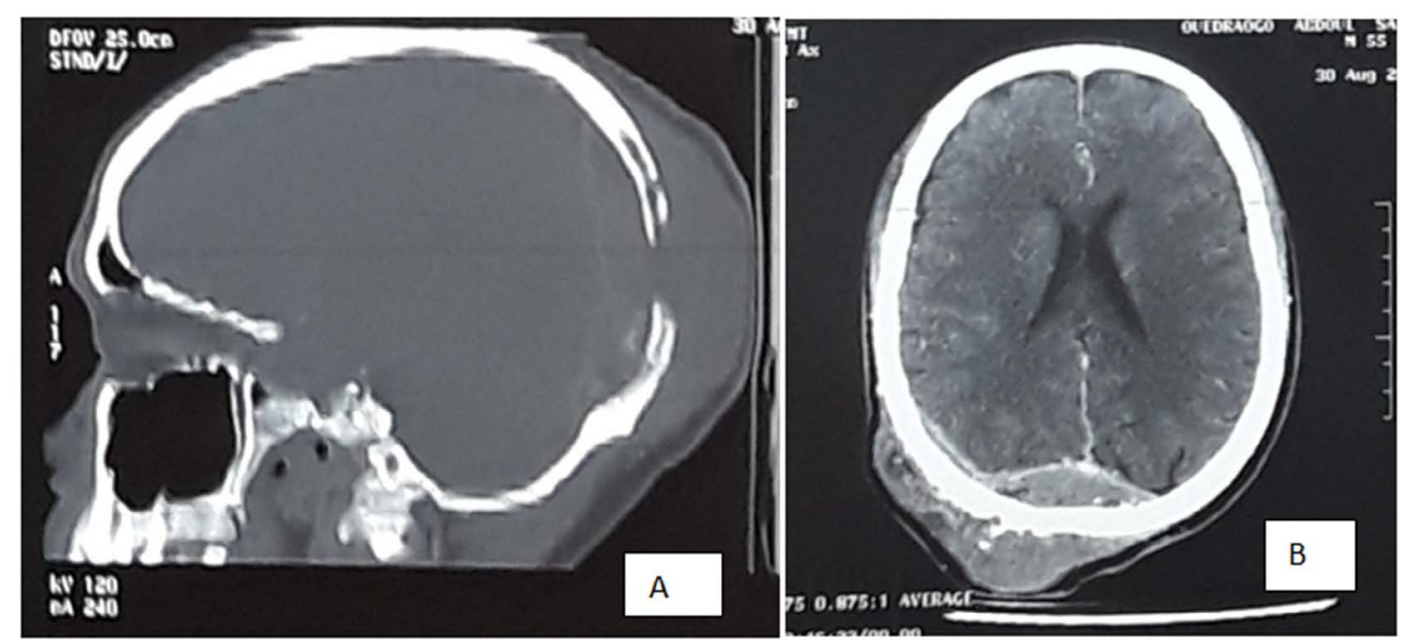

Figure 3: Brain CT showing occipital osteolytic metastatic lesions A) Bone window depicting discontinuity of the two occipital plates; B) Soft tissue window showing intracranial mass compressing on the brain parenchyma. 
of the skull without obvious cause in a man above 60 years old should raise the suspicion of cancer of the prostate. For Starc, et al. secondary tumors of the skull are usually acute in onset and less painful [7]. Mass in the base of the skull may present with neurological deficit depending on the bone involved and contiguous nerve structures compressed. The clinical features may not be due to metastasis to the nerve tissue, but the manifestation may be due to compression or infiltration of the nerve tissue by neoplastic processes. In this series, there is no direct secondary deposit on the brain tissue. This showed that secondary metastases to the brain tissue are rare. In a study of over 43 patients with metastatic prostate cancer to the base of the skull, Greenberg, et al. [8] identified 5 clinical syndromes related to the localization of the lesions: orbital, parasellar, middle-fossa, jugular foramen and occipital condyle syndromes. However, there were some isolated signs which cannot be associated with any of the syndromes described by Greenberg. This was the scenario in the second case presented in our series who had a temporal bone metastasis with involvement of petrous bone leading to a unilateral hearing loss.

Isolated skull metastasis in prostate cancer are rare; some autopsy series reported less than 6\% [3]. In our series, two of the patients who had whole body bone scan showed involvement of bones other than the skull (limbs and ribs). The predilection of prostate cancer to the skull may be due to Batson's venous plexus that connects prostate with the skull through epidural and dural veins [9]. Therefore, there should be deliberate attempt at assessing possibility of skull metastasis in all patients with advanced prostate cancer. High levels of PSA in all the patients suggest advanced stage of the disease and strongly raise the suspicion of bone metastasis. At metastatic stage, treatment of prostate cancer is mainly palliation which may consist of androgen deprivation with or without anti-androgen such as Abiraterone acetate and Cyproterone [10]. There may be place of chemotherapy in some select cases. Androgen deprivation may lead to osteopenia that should be addressed by a specific treatment focusing on the bone. Most of these newer treatment options are not affordable for most of our patients as was seen in some of the patients in our series. Even though orchiectomy is cheap and very effective means of androgen deprivation, many patients turn down this offer as was seen in two of the cases in this study.

The rise of PSA level despite a drop in testosterone levels seen in the first and third patient in this series may mean the beginning of resistance to castration. These patients could have benefited from second-line anti-androgen therapy such as Abiraterone or Enzalut- amide; cytotoxic drug such as Docetaxel or Carbazitaxel or immunotherapy using vaccine such as Sipuleucel-T [10].

\section{Conclusion}

Skull swelling can be rare presentation of prostate cancer. Any recent and rapidly growing skull swelling in a man above 60 -years-old should raise the suspicion of occult prostate cancer. There must be deliberate attempt at ruling out skull metastasis in all patients with advanced cancer of the prostate.

\section{Conflicts of Interest}

The authors declare that there are no conflicts of interest regarding the publication of this paper.

\section{Authors' Contributions}

All the authors have made contribution to the conception and have been involved in revising the manuscript critically. They have given final approval for the version to be published.

\section{References}

1. Bray F, Ferlay J, Soerjomataram I, Siegel RL, Torre LA, et al. (2018) Global cancer statistics 2018: GLOBOCAN estimates of incidence and mortality worldwide for 36 cancers in 185 countries. CA Cancer J Clin 68: 394-424.

2. Bienz M, Saad F (2015) Management of bone metastases in prostate cancer: A review. Curr Opin Support Palliat Care 9: $261-267$.

3. Saitoh H, Hida M, Shimbo T, Nakamura K, Yamagata J, et al. (1984) Metastatic patterns of prostatic cancer. Correlation between sites and number of organs involved. Cancer 54: 3078-3084.

4. Long MA, Husband JE (1999) Features of unusual metastases from prostate cancer. Br J Radiol 72: 933-941.

5. Mitsuya K, Nakasu Y, Horiguchi S, Harada H, Nishimura T, et al. (2011) Metastatic skull tumors: MRI features and a new conventional classification. J Neurooncol 104: 239245.

6. Laigle-Donadey F, Taillibert S, Martin-Duverneuil N, Hildebrand J, Delattre JY (2005) Skull-base metastases. J Neurooncol 75: 63-69.

7. Stark AM, Eichmann T, Mehdorn HM (2003) Skull metastases: Clinical features, differential diagnosis, and review of the literature. Surg Neurol 60: 219-225.

8. Greenberg HS, Deck MD, Vikram B, Chu FC, Posner JB (1981) Metastasis to the base of the skull: clinical findings in 43 patients. Neurology 31: 530-537.

9. Batson OV (1940) The function of the vertebral veins and their role in the spread of metastases. Ann Surg 112: 138149.

10. Rozet F, Hennequin C, Beauval JB, Beuzeboc P, Cormier L, et al. (2018) [French ccAFU guidelines - Update 20182020: Prostate cancer]. Prog Urol 28: S79-S130.

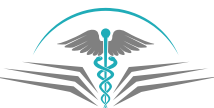

